\title{
Model of a system for the capacitive measurement of the height of liquids in metallic tanks
}

\author{
R. C. Callarotti \\ Universidad del Turabo, Puerto Rico
}

\begin{abstract}
We analyze the problem of the capacitive measurement of the height of a liquid in a cylindrical storage tank whose outer structure is connected to the ground. The system is excited electrically by applying a time varying voltage between a disk shaped electrode (located at the centre of the tank) and the external tank wall. The theoretical solution for the pertinent Maxwell's equations is derived for a liquid characterized by a given real permittivity $\varepsilon_{\mathrm{L}}$ and zero conductivity. The space above the liquid is air. The problem is reduced to the solution of the Laplace equation for a multiply connected region. The validity of the analytical solution is checked against a numerical based on an equivalent circuit for the system. The case where the liquid is considered as having a given conductivity is also considered. Finally, we include a discussion concerning the application of this type of instrumentation in the case of storage tanks used in the petroleum industry.

Keywords: inductive measurements, numerical procedures, oil production.
\end{abstract}

\section{Introduction}

The present paper is concerned with determining the level of liquid inside a cylindrical metallic tank, by measuring the electrical impedance between a metallic electrode located at the center of the tank. The geometry of the system considered is shown on Figure 1(a). The tank (radius a), is connected to ground. Inside the tank there is a liquid with relative real permittivity $\varepsilon_{\mathrm{L}}$ up to a height $\mathrm{H}$. The liquid is assumed to have zero conductivity. The volume over the liquid is characterized as having a real permittivity $\varepsilon_{S}$ and zero conductivity. A potential 
$\mathrm{V}(\mathrm{t})$ is applied to a metal disk (with radius $\mathrm{b}$ and thickness $\mathrm{d}$ ) located at the center of the tank at a distance $\mathrm{z}_{0}$ from the top.

$$
\mathrm{V}(\mathrm{t})=\mathrm{V}_{0} \exp (j \omega \mathrm{t})
$$

where $\mathrm{V}_{0}$ is the amplitude of the applied voltage, and $\omega$ is the excitation angular frequency. It is understood that the applied physical voltage corresponds to the real part of $\mathrm{V}(\mathrm{t})$, and that the essence of the present work corresponds to the determination of the real part of the current $\mathrm{I}(\mathrm{t})$ that will flow between the central electrode and ground. We determine the dependence of this current on the height of the liquid in the tank, and its dependence on the liquid properties.

In the case of tanks used in the oil industry (in particular for crude oil), the level of liquids inside a tank is generally determined by simple mechanical systems (a float connected to an external indicator), although some systems measure the capacitance between an internal electrode and the tank walls (Schuler [1]). Figure 1(a) shows the geometry of the system considered in this paper, while Figures 1(b) and 1(c) show the electrode arrangement for discontinuous and continuous level measurements.

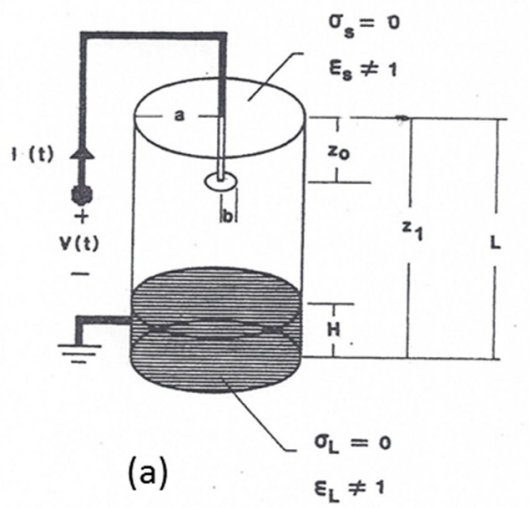

(b)
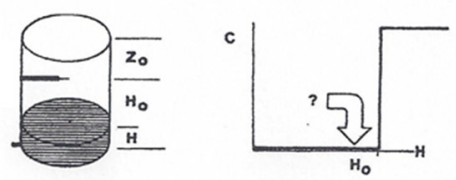

(c)
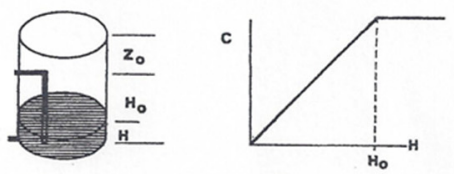

Figure 1: (a) Geometry of the system considered in this paper, (b) discontinuous level measurements and (c) continuous measurement with electrode placed in the liquid.

In this paper we determine analytically the admittance between the internal cylindrical electrode and the tank wall. We compare this solution with a numerical finite difference solution.

\section{Potential distribution}

For convenience, the structure to be analyzed is inverted (as shown in figure 2). We consider a range of frequencies where quasi-static Maxwell equations can be applied. They are: 
Zone $1\left(\mathrm{z}<\mathrm{z}_{0}\right)$

Zone $2\left(\mathrm{z}_{0}<\mathrm{z}<\mathrm{z}_{1}\right)$

Zone $3\left(\mathrm{z}_{1}<\mathrm{z}<\mathrm{L}\right)$

$$
\begin{aligned}
& \vec{\nabla} \times \overrightarrow{\mathrm{E}}_{1}=0 \\
& \vec{\nabla} \cdot \overrightarrow{\mathrm{E}}_{1}=0
\end{aligned}
$$

The solution to equations (2) to (7) can be found in terms of three scalar potentials $\Phi_{1}, \Phi_{2}$, and $\Phi_{3}$, that must satisfy the corresponding Laplace equations:

$$
\begin{gathered}
\vec{\nabla}^{2} \Phi_{1}(\rho, z)=0 \text { for } \quad \mathrm{z}<\mathrm{z}_{0} \\
\vec{\nabla}^{2} \Phi_{2}(\rho, z)=0 \text { for } \mathrm{z}_{1}>\mathrm{z}>\mathrm{z}_{0} \\
\vec{\nabla}^{2} \Phi_{3}(\rho, z)=0 \text { for } \mathrm{z}>\mathrm{z}_{1}
\end{gathered}
$$

Zone 1 is separated from zone 2 , by the metal disk of radius b and thickness $\mathrm{d}$ $(\mathrm{d} \sim 0)$, situated at $\mathrm{z}=\mathrm{z}_{0}$. The solutions of equations (8), (9) and (10) are (Jackson [2]):

$$
\begin{gathered}
\Phi_{1}(\rho, z)=\sum_{m} A_{m} J_{0}\left(k_{m} \rho\right) \sinh \left(k_{m} z\right) \\
\Phi_{2}(\rho, z)=\sum_{m} J_{0}\left(k_{m} \rho\right)\left(B_{m} \exp \left(k_{m} z\right)+C_{m} \exp \left(-k_{m} z\right)\right) \\
\Phi_{3}(\rho, z)=\sum_{m} D_{m} J_{0}\left(k_{m} \rho\right) \sinh \left(k_{m}(L-z)\right)
\end{gathered}
$$

where $J_{0}$ is the Bessel function of the first kind and order 0 , and $k_{m}$ are the $m$ discrete roots of $J_{0}=0-A$ bramowitz and Stegun [3]. The constants $A_{m}, B_{m}, C_{m}$, and $\mathrm{D}_{\mathrm{m}}$ are to be evaluated by the following boundary conditions:

$$
\begin{array}{ll}
\Phi_{1,2,3}(\mathrm{a}, \mathrm{z})=0 & \Phi_{1,2,3}(0, \mathrm{z}) \quad \text { finite } \\
\Phi_{1}(\rho, 0)=0 & \\
\Phi_{3}(\rho, \mathrm{L})=0 &
\end{array}
$$

Additional conditions are required by the continuity of the potentials at $\mathrm{z}=\mathrm{Z}_{1}$, and at $\mathrm{z}=\mathrm{Z}_{0}$ and continuity of the normal electrical density components at $\mathrm{z}_{1}$ :

$$
\begin{array}{ll}
\Phi_{2}\left(\rho, z_{1}\right)=\Phi_{3}\left(\rho, z_{1}\right) 0 & \Phi_{1}\left(\rho, z_{0}\right)=\Phi_{2}\left(\rho, z_{0}\right) \\
\left.\varepsilon_{L} \frac{\partial \Phi_{2}}{\partial z}\right|_{z 1}=\left.\varepsilon_{S} \frac{\partial \Phi_{3}}{\partial z}\right|_{z 1} & \Phi_{3}(\rho, L)=0
\end{array}
$$

An additional equation is required corresponding to the boundary condition at $\mathrm{z}_{0}$ (on the electrode). 
As we discuss in detail in the next section, we have solved the problem via two different approaches.

Approach A: we assume that the potential $V\left(\rho, z_{0}\right)$ the plane $z=z_{0}$ is known. The capacitance is reduced to the solution of:

$$
\Phi\left(\rho, z_{0}\right)=V\left(\rho, z_{0}\right)
$$

This problem is simpler as we have separated two different regions (above and below the electrode plane), and the corresponding Laplace equation solutions are given in most basic electromagnetism textbooks like Stratton [4] and Smythe [5].

Approach B: we assume that the surface charge density of the electrode in given by a known function $\eta(\rho)$ and the corresponding equation for the normal components of the electrical density is:

$$
\varepsilon_{\mathrm{L}}\left[\frac{\partial \Phi_{1}}{\partial \mathbf{z}}-\frac{\partial \Phi_{2}}{\partial \mathbf{z}}\right]_{\mathrm{z}=\mathrm{z} 0}=\eta(\rho)
$$

In the following section we determine $V\left(\rho, z_{0}\right)$ and $\eta(\rho)$ by means of a variational scheme.

\section{Capacitance calculations}

Following Collin [6] we find the capacitance of the system in accordance to two different schemes: a) minimizing the capacitance expressed in terms of the electrical energy stored and thus determine $V(\rho, z o), b)$ determining $\eta(\rho)$ using Green's functions.

\subsection{Capacitance calculation according to scheme (a)}

We consider first a finite thickness electrode as shown in Figure 2. The general solution for Laplace equation in zone 4 is:

$$
\begin{aligned}
& \Phi=\Phi_{0}+\Phi_{\mathrm{X}} \text { where } \Phi_{0}=\mathrm{V}_{0} \frac{\ln (\rho / \mathrm{a})}{\ln (\mathrm{b} / \mathrm{a})} \\
& \Phi_{\mathrm{X}}=\sum_{\mathrm{n}}\left[\mathrm{a}_{\mathrm{n}} \mathrm{J}_{0}\left(\mathrm{k}_{\mathrm{n}} \rho\right)+\mathrm{b}_{\mathrm{n}} \mathrm{Y}_{0}\left(\mathrm{k}_{\mathrm{n}} \rho\right)\right]\left[\mathrm{c}_{\mathrm{n}} \exp \left(\mathrm{k}_{\mathrm{n}} \mathrm{z}\right)+\mathrm{d}_{\mathrm{n}} \exp \left(-\mathrm{k}_{\mathrm{n}} \mathrm{z}\right)\right]
\end{aligned}
$$

$\Phi_{0}$ represents the limiting trivial solution when there are no variations in $\mathrm{z}$ :

$$
\frac{1}{\rho} \frac{\partial}{\partial \rho}\left(\rho \frac{\partial \Phi_{0}}{\partial \rho}\right)=0
$$

$\mathrm{k}_{\mathrm{n}}$ are the values that satisfy the boundary conditions:

$$
\Phi_{0}(\mathrm{~b}, \mathrm{z})=0 \quad \Phi_{\mathrm{X}}(\mathrm{a}, \mathrm{z})=0
$$

Substitution of these conditions in equation (25) yields:

$$
a_{n}\left[J_{0}\left(k_{n} a\right)-J_{0}\left(k_{n} b\right) / Y_{0}\left(k_{n} a\right)\right]=0
$$




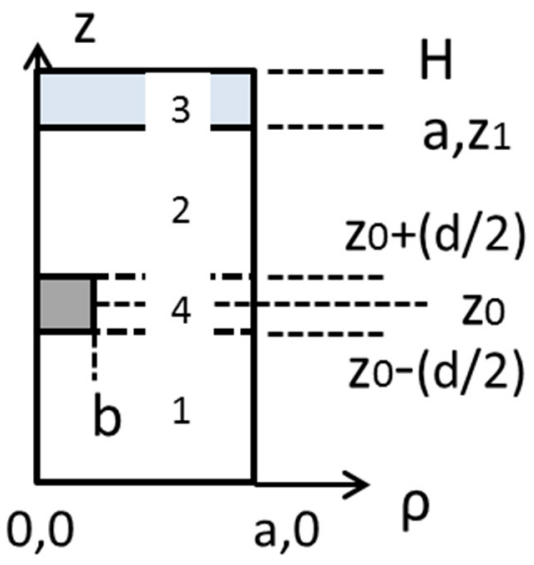

Figure 2: $\quad$ Tank details when the electrode thickness $(d \neq 0)$ is considered.

Thus the $\mathrm{k}_{\mathrm{n}}$ are the roots of:

$$
\left[J_{0}\left(k_{n} a\right) Y_{0}\left(k_{n} b\right)-J_{0}\left(k_{n} b\right) Y_{0}\left(k_{n} a\right)\right]=0
$$

In the limit $\mathrm{d} \rightarrow 0$ then $\mathrm{z} \rightarrow \mathrm{z}_{0}$ and we rewrite Eq. (24) as:

$$
\Phi=\Phi_{0}+\sum_{\mathrm{n}} \mathrm{a}_{\mathrm{n}}\left[\mathrm{J}_{0}\left(\mathrm{k}_{\mathrm{n}} \rho\right)-\left\{\mathrm{J}_{0}\left(\mathrm{k}_{\mathrm{n}} \mathrm{b}\right) / \mathrm{Y}_{0}\left(\mathrm{k}_{\mathrm{n}} \mathrm{b}\right)\right\} \mathrm{Y}_{0}\left(\mathrm{k}_{\mathrm{n}} \rho\right)\right]=\mathrm{V}\left(\rho, \mathrm{z}_{0}\right)
$$

Now we determine the $A_{m}$ as functions of the $a_{n}$, formally writing:

$$
\begin{gathered}
\sum_{\mathrm{m}} \mathrm{A}_{\mathrm{m}} \mathrm{J}_{0}\left(\mathrm{k}_{\mathrm{m}} \rho\right) \sinh \left(\mathrm{k}_{\mathrm{m}} \mathrm{z}_{0}\right)=\mathrm{V}_{0} \text { for } \rho<\mathrm{b} \\
\sum_{\mathrm{m}} \mathrm{A}_{\mathrm{m}} \mathrm{J}_{0}\left(\mathrm{k}_{\mathrm{m}} \rho\right) \sinh \left(\mathrm{k}_{\mathrm{m}} \mathrm{z}_{0}\right)=\Phi\left(\rho, \mathrm{z}_{0}\right) \text { for } \rho>b
\end{gathered}
$$

In view of the orthogonality of the Bessel functions we can obtain:

$$
\begin{aligned}
& \mathrm{A}_{\mathrm{m}}=\delta \mathrm{m}_{0}+\sum_{\mathrm{n}} \mathrm{a}_{\mathrm{n}}\left(\delta \mathrm{m}_{\mathrm{n}}\right) \\
& \delta \mathrm{m}_{0} \equiv \frac{2 \mathrm{~J}_{0}\left(\mathrm{k}_{\mathrm{m}} \mathrm{b}\right) \mathrm{V}_{0}}{\mathrm{a}^{2} \mathrm{~J}_{1}^{2}\left(\mathrm{k}_{\mathrm{m}} \mathrm{a}\right) \sinh \left(\mathrm{k}_{\mathrm{m}_{0}}\right) \mathrm{k}_{\mathrm{m}}^{2}(\ln (\mathrm{a} / \mathrm{b}))} \\
& \delta \mathrm{m}_{\mathrm{n}} \equiv \frac{4 \mathrm{~J}_{0}\left(\mathrm{k}_{\mathrm{m}} \mathrm{b}\right)}{\pi \mathrm{a}^{2} \mathrm{~J}_{1}^{2}\left(\mathrm{k}_{\mathrm{m}^{\mathrm{a}}} \mathrm{a}\right) \sinh \left(\mathrm{k}_{\mathrm{m}_{0}} \mathrm{z}_{0}\right)\left(\mathrm{k}_{\mathrm{m}}^{2}-\mathrm{k}_{\mathrm{n}}^{2}\right) \mathrm{Y}_{0}\left(\mathrm{k}_{\mathrm{n}} \mathrm{b}\right)}
\end{aligned}
$$

where $\mathrm{n}$ corresponds to the number of each root of equation (28).

Under the quasi static approximation used $|E|^{2}=(\delta \Phi / \delta \rho)^{2}+(\delta \Phi / \delta z)^{2}$, so that the total electrical energy stored in the tank will be the sum of the energies $\mathrm{W}_{1}, \mathrm{~W}_{2}$, and $\mathrm{W}_{3}$ corresponding to each region: 


$$
\begin{aligned}
& \mathrm{W}_{1}=\pi \varepsilon_{\mathrm{s}} \int_{0}^{\mathrm{z}_{0}} \mathrm{dz} \int_{0}^{\mathrm{a}} \rho \mathrm{d} \rho\left\{\left[\frac{\partial \phi_{1}}{\partial \mathrm{z}}\right]^{2}+\left[\frac{\partial \phi_{1}}{\partial \rho}\right]^{2}\right\} \\
& \mathrm{W}_{2}=\pi \varepsilon_{\mathrm{S}_{\mathrm{z}}}^{\mathrm{z}_{1}} \mathrm{dz} \int_{0}^{\mathrm{a}} \rho \mathrm{d} \rho\left\{\left[\frac{\partial \phi_{2}}{\partial \mathrm{z}}\right]^{2}+\left[\frac{\partial \phi_{2}}{\partial \rho}\right]^{2}\right\} \\
& \mathrm{W}_{3}=\pi \varepsilon_{\mathrm{L}_{\mathrm{z}_{1}}}^{\mathrm{L}} \mathrm{dz} \int_{0}^{\mathrm{a}} \rho \mathrm{d} \rho\left\{\left[\frac{\partial \phi_{3}}{\partial \mathrm{z}}\right]^{2}+\left[\frac{\partial \phi_{3}}{\partial \rho}\right]^{2}\right\}
\end{aligned}
$$

Replacing the expressions for the $\varphi$ 's we obtain:

$$
\begin{gathered}
\mathrm{W}_{1}=\frac{\pi \varepsilon}{2} \sum_{\mathrm{m}} \mathrm{a}^{2} \mathrm{~A}_{\mathrm{m}}^{2} \mathrm{k}_{\mathrm{m}}\left\{\left[\mathrm{J}_{1}^{2}+\mathrm{J}_{2}^{2}\right] \sinh \left(2 \mathrm{k}_{\mathrm{m}} \mathrm{z}_{0}\right)+\left(\mathrm{J}_{1}^{2}+\mathrm{J}_{2}^{2}\right) \mathrm{k}_{\mathrm{m}_{0}} \mathrm{z}_{0}\right\} \\
\mathrm{W}_{2}=\frac{\pi \varepsilon_{\mathrm{L}}}{2} \sum_{\mathrm{m}} 2 \mathrm{a}^{2} \mathrm{k}_{\mathrm{m}}^{2}\left\{\left[\mathrm{~J}_{1}^{2}-\mathrm{J}_{2}^{2}\right] \mathrm{B}_{\mathrm{m}} \mathrm{C}_{\mathrm{m}}\left(\mathrm{z}_{1}-\mathrm{z}_{0}\right)\right\} \\
+\frac{\pi \varepsilon}{2} \sum_{\mathrm{m}} 2 \mathrm{a}^{2} \mathrm{k}_{\mathrm{m}}^{2}\left\{\frac{\mathrm{a}^{2} \mathrm{k}_{\mathrm{m}}^{2}}{2}\left[\mathrm{~J}_{1}^{2}+\mathrm{J}_{2}^{2}\right]\left[\mathrm{B}_{\mathrm{m}}^{2}\left(\mathrm{e}^{2 \mathrm{k}_{\mathrm{m}} \mathrm{z}_{1}}-\mathrm{e}^{2 \mathrm{k}_{\mathrm{m}} \mathrm{z}_{0}}\right)+\mathrm{C}_{\mathrm{m}}^{2}\left(\mathrm{e}^{-2 \mathrm{k}_{\mathrm{m}} \mathrm{z}_{0}}-\mathrm{e}^{-2 \mathrm{k}_{\mathrm{m}} \mathrm{z}_{1}}\right)\right\}\right. \\
\mathrm{W}_{3}=\frac{\pi \varepsilon_{\mathrm{L}}}{2} \sum_{\mathrm{m}} \mathrm{D}_{\mathrm{m}}^{2} \mathrm{a}^{2} \mathrm{k}_{\mathrm{m}}^{2}\left\{\left[\mathrm{~J}_{1}^{2}+\mathrm{J}_{2}^{2}\right] \sinh \left(2 \mathrm{k}_{\mathrm{m}}\left(\mathrm{L}-\mathrm{z}_{1}\right)\right)(1 / 4)+\left(\mathrm{J}_{1}^{2}-\mathrm{J}_{2}^{2}\right) \mathrm{k}_{\mathrm{m}}\left(\mathrm{L}-\mathrm{z}_{1}\right)(1 / 2)\right\}
\end{gathered}
$$

We define the relationship of the constants $B_{m}=\delta_{B} A_{m}, C_{m}=\delta_{C} A_{m}, D_{m}=\delta_{D} A_{m}$, in terms of the different deltas that are then determined from the boundary conditions. We then obtain:

$$
\begin{gathered}
\delta_{\mathrm{B}}=\sinh \left(\mathrm{k}_{\mathrm{m}^{\mathrm{z}}}\right) \exp \left(-\mathrm{k}_{\mathrm{m}} \mathrm{z}_{1}\right)\left\{\delta \cosh \left[\mathrm{k}_{\mathrm{m}}\left(\mathrm{L}-\mathrm{z}_{1}\right)\right]-\sinh \left[\mathrm{k}_{\mathrm{m}}\left(\mathrm{L}-\mathrm{z}_{1}\right)\right]\right\} / \Delta \\
\delta_{\mathrm{C}}=\sinh \left(\mathrm{k}_{\mathrm{m}} \mathrm{z}_{0}\right) \exp \left(+\mathrm{k}_{\mathrm{m}} \mathrm{z}_{1}\right)\left\{-\delta \cosh \left[\mathrm{k}_{\mathrm{m}}\left(\mathrm{L}-\mathrm{z}_{1}\right)\right]-\sinh \left[\mathrm{k}_{\mathrm{m}}\left(\mathrm{L}-\mathrm{z}_{1}\right)\right]\right\} / \Delta \\
\delta_{\mathrm{D}}=-2 \sinh \left(\mathrm{k}_{\mathrm{m} \mathrm{z}_{0}}\right) / \Delta
\end{gathered}
$$

where $\Delta$ is given by:

$$
\Delta=2 \delta \cosh \left[\mathrm{k}_{\mathrm{m}}\left(\mathrm{L}-\mathrm{z}_{1}\right)\right] \sinh \left[\mathrm{k}_{\mathrm{m}}\left(\mathrm{z}_{0}-\mathrm{z}_{1}\right)\right]+2 \sinh \left[\mathrm{k}_{\mathrm{m}}\left(\mathrm{L}-\mathrm{z}_{1}\right)\right] \cosh \left[\mathrm{k}_{\mathrm{m}}\left(\mathrm{z}_{0}-\mathrm{z}_{1}\right)\right]
$$


$\mathrm{W}_{\mathrm{e}}$ can be written as: $\mathrm{W}_{\mathrm{e}}=(1 / 2) \varepsilon_{\mathrm{S}} \pi \mathrm{a}^{2} \sum_{\mathrm{m}} \mathrm{A}_{\mathrm{m}}^{2} \mathrm{~g}_{\mathrm{m}} \mathrm{k}_{\mathrm{m}}$, where $\mathrm{g}_{\mathrm{m}}$ is defined by:

$$
\begin{aligned}
& \frac{4 \mathrm{~g}_{\mathrm{m}}}{\left(\mathrm{J}_{1}^{2}+\mathrm{J}_{2}^{2}\right)}= \\
& +\left\{\left[\left(\sinh \left(2 \mathrm{k}_{\mathrm{m}} \mathrm{z}_{0}\right)+\delta_{\mathrm{D}}^{2} \sinh \left[2 \mathrm{k}_{\mathrm{m}}\left(\mathrm{L}-\mathrm{z}_{1}\right)\right]+2 \delta_{\mathrm{B}}^{2}\left[\mathrm{e}^{+2 \mathrm{k}_{\mathrm{m}} \mathrm{z}_{0}}-\mathrm{e}^{+2 \mathrm{k}_{\mathrm{m}} \mathrm{z}_{1}}\right]+2 \delta_{\mathrm{C}}^{2}\left[\mathrm{e}^{-2 \mathrm{k}_{\mathrm{m}} \mathrm{z}_{0}}-\mathrm{e}^{-2 \mathrm{k}_{\mathrm{m}} \mathrm{z}_{1}}\right]\right\}\right.\right. \\
& +\frac{2\left(\mathrm{~J}_{1}^{2}-\mathrm{J}_{2}^{2}\right)}{\left(\mathrm{J}_{1}^{2}+\mathrm{J}_{2}^{2}\right)}\left\{\mathrm{k}_{\mathrm{m}} \mathrm{z}_{0}+\delta_{\mathrm{B}} \delta_{\mathrm{D}} \mathrm{k}_{\mathrm{m}}\left(\mathrm{L}-\mathrm{z}_{1}\right)-4 \delta_{\mathrm{B}} \delta_{\mathrm{C}} \mathrm{k}_{\mathrm{m}}\left(\mathrm{z}_{1}-\mathrm{z}_{0}\right)\right\}
\end{aligned}
$$

$\mathrm{W}_{\mathrm{e}}$ is now minimized with respect to the $\mathrm{a}_{\mathrm{n}}$ 's (included in the $\mathrm{A}_{\mathrm{m}}$ 's). This process is equivalent to minimizing the capacitance since:

$$
\frac{\partial \mathrm{w}_{\mathrm{e}}}{\partial \mathrm{a}_{\mathrm{n}}}=\frac{\partial(1 / 2) \mathrm{CV}_{0}^{2}}{\partial \mathrm{a}_{\mathrm{n}}} \quad \Rightarrow \Rightarrow \frac{\partial \mathrm{C}}{\partial \mathrm{a}_{\mathrm{n}}}=0 \Rightarrow \Rightarrow \text { system of } \mathrm{n} \text { equations }
$$

Figure 3 shows the results for the capacitance of electrode $b$ as a function of the radius $\left(\varepsilon_{\mathrm{L}}=\varepsilon_{\mathrm{S}}\right)$. As the number of constants is increased the capacitance tends to a limiting correct value.

\subsection{Capacitance calculation by means of Green's function}

The Green function for a unit point charge located at $\left(\rho_{1}, z_{1}, \varphi_{1}\right)$ is the solution (Jackson [2]), of the equation:

$$
\nabla^{2} \mathrm{G}\left(\overrightarrow{\mathrm{r}}, \vec{r}_{1}\right)=-(1 / \varepsilon) \delta\left(\mathrm{z}-\mathrm{z}_{1}\right) \delta\left(\rho-\rho_{1}\right) /(2 \pi \rho)
$$

When the center electrode is thin, the presence of a point charge is equivalent to a boundary condition given by:

$$
\varepsilon\left[-\frac{\partial \mathrm{G}_{2}}{\partial \mathrm{z}}+-\frac{\partial \mathrm{G}_{1}}{\partial \mathrm{z}}\right]=\delta\left(\rho-\rho_{1}\right) /(2 \pi \rho)
$$

The Green function will have the values: $G_{1}, G_{2}$ and $G_{3}$, for the different tank regions. They are obtained from equations analogous to equations (14), (15), and (16), when the boundary conditions (equation (18)) are applied. The following expressions for the constants $A_{m}, B_{m}, C_{m}$ and $D_{m}$ are found:

$$
\mathrm{A}_{\mathrm{m}}=\mathrm{F} \frac{\cosh \left[\mathrm{k}_{\mathrm{m}}\left(\mathrm{z}_{1}-\mathrm{z}_{0}\right)\right] \delta \tanh \left[\mathrm{k}_{\mathrm{m}}\left(\mathrm{z}_{1}-\mathrm{z}_{0}\right)\right]-\tanh \left[\mathrm{k}_{\mathrm{m}}\left(\mathrm{L}-\mathrm{z}_{1}\right)\right]}{\cosh \left[\mathrm{k}_{\mathrm{m}} \mathrm{z}_{1}\right]\left\{\delta \tanh \left[\mathrm{k}_{\mathrm{m}} \mathrm{z}_{1}\right]-\tanh \left[\mathrm{k}_{\mathrm{m}}\left(\mathrm{L}-\mathrm{z}_{1}\right)\right]\right\}}
$$

where $\quad \mathrm{F}=\frac{\mathrm{J}_{0}\left(\mathrm{k}_{\mathrm{n})}\right.}{\pi \varepsilon_{\mathrm{s}} \mathrm{a}^{2} \mathrm{k}_{\mathrm{m}} \mathrm{J}_{1}^{2}\left(\mathrm{k}_{\mathrm{m}} \mathrm{a}\right)}$

$$
\mathrm{B}_{\mathrm{m}}=-\mathrm{F} \frac{\sinh \left(\mathrm{k}_{\mathrm{m}} \mathrm{z}_{0}\right) \exp \left(-\mathrm{k}_{\mathrm{m}} \mathrm{z}_{1}\right)\left\{\delta+\tanh \left[\mathrm{k}_{\mathrm{m}}\left(\mathrm{L}-\mathrm{z}_{1}\right)\right]\right\}}{2 \cosh \left[\mathrm{k}_{\mathrm{m}} \mathrm{z}_{1}\right]\left\{\delta \tanh \left[\mathrm{k}_{\mathrm{m}} \mathrm{z}_{1}\right]-\tanh \left[\mathrm{k}_{\mathrm{m}}\left(\mathrm{L}-\mathrm{z}_{1}\right)\right]\right\}}
$$




$$
\begin{gathered}
\mathrm{C}_{\mathrm{m}}=\mathrm{F} \frac{\sinh \left(\mathrm{k}_{\mathrm{m}} \mathrm{z}_{0}\right) \exp \left(-\mathrm{k}_{\mathrm{m}} \mathrm{z}_{1}\right)\left\{\delta-\tanh \left[\mathrm{k}_{\mathrm{m}}\left(\mathrm{L}-\mathrm{z}_{1}\right)\right]\right\}}{2 \cosh \left[\mathrm{k}_{\mathrm{m}} \mathrm{z}_{1}\right]\left\{\delta \tanh \left[\mathrm{k}_{\mathrm{m}} \mathrm{z}_{1}\right]-\tanh \left[\mathrm{k}_{\mathrm{m}}\left(\mathrm{L}-\mathrm{z}_{1}\right)\right]\right\}} \\
\mathrm{D}_{\mathrm{m}}=\frac{-\mathrm{F} \sinh \left(\mathrm{k}_{\mathrm{m}} \mathrm{z}_{0}\right)}{\cosh \left[\mathrm{k}_{\mathrm{m}}\left(\mathrm{z}_{1}\right)\right] \cosh \left[\mathrm{k}_{\mathrm{m}}\left(\mathrm{L}-\mathrm{z}_{1}\right)\right]\left\{\delta \tanh \left[\mathrm{k}_{\mathrm{m}} \mathrm{z}_{1}\right]-\tanh \left[\mathrm{k}_{\mathrm{m}}\left(\mathrm{L}-\mathrm{z}_{1}\right)\right]\right\}}
\end{gathered}
$$

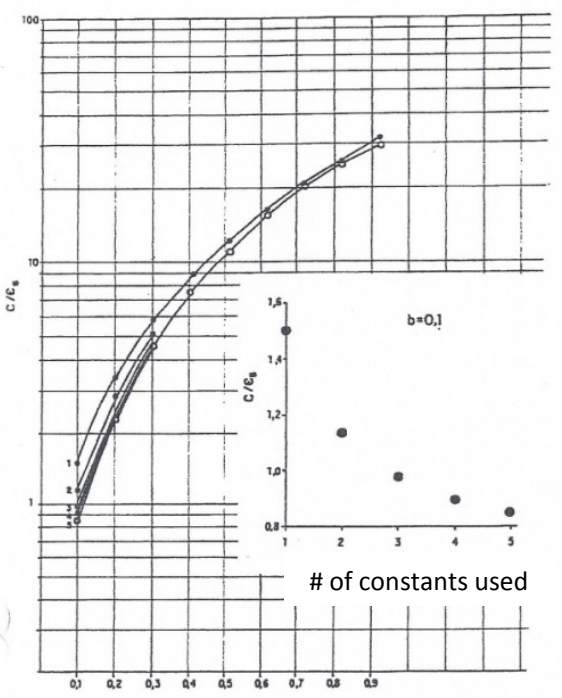

Figure 3: Capacitance $/ \varepsilon_{\mathrm{s}}$ vs. internal electrode diameter. The insert shows the dependence of the results as a function of the number of constants used. As the number of constants increases the capacitance tends to a constant value.

The capacitance is then given by:

$$
\begin{gathered}
\frac{\varepsilon_{\mathrm{S}}}{\mathrm{C}}=\left(\frac{4 \mathrm{a}}{\pi \mathrm{b}^{2}}\right) \sum_{\mathrm{m}} \frac{\mathrm{J}_{1}^{2}\left(\mathrm{k}_{\mathrm{m}} \mathrm{b}\right)}{\left(\mathrm{k}_{\mathrm{m}} \mathrm{a}\right)^{3} \mathrm{~J}_{1}^{2}\left(\mathrm{k}_{\mathrm{m}} \mathrm{a}\right)} \mathrm{H}_{\mathrm{m}} \\
\mathrm{H}_{\mathrm{m}}=\left\{\frac{\sinh \left(\mathrm{k}_{\mathrm{m}} \mathrm{z}_{0}\right) \delta \sinh \left[\mathrm{k}_{\mathrm{m}}\left(\mathrm{z}_{1}-\mathrm{z}_{0}\right)-\tanh \left[\mathrm{k}_{\mathrm{m}}\left(\mathrm{L}-\mathrm{z}_{1}\right)\right] \cosh \left[\mathrm{k}_{\mathrm{m}}\left(\mathrm{z}_{1}-\mathrm{z}_{0}\right)\right.\right.}{\delta \sinh \left[\mathrm{k}_{\mathrm{m}} \mathrm{z}_{1}\right]-\cosh \left[\mathrm{k}_{\mathrm{m}} \mathrm{z}_{1}\right] \tanh \left[\mathrm{k}_{\mathrm{m}}\left(\mathrm{L}-\mathrm{z}_{1}\right)\right]}\right\}
\end{gathered}
$$

In the following section we present the results of the capacitance of the tank for different radii of the central electrode and the capacitance measured as a function of liquid content. In both cases we compare the results of the theory discussed with the numerical results obtained by replacing each elementary 
volume element by an R-C circuit, and considering 29x29 nodes. The equivalent circuit used is the low frequency approximation of Kron model [7].

\subsection{Results}

In this section we present in Figure 4, the theoretical results of the calculation of the capacitance measured at the central electrode as a function of the radius of the central electrode.

In Figure 5 we show the behavior of the capacitance of the tank as the height of the liquid is increased. As in the case of the capacitance dependence on the radius of the central electrode we find excellent agreement between our theoretical solutions and the numerical results.

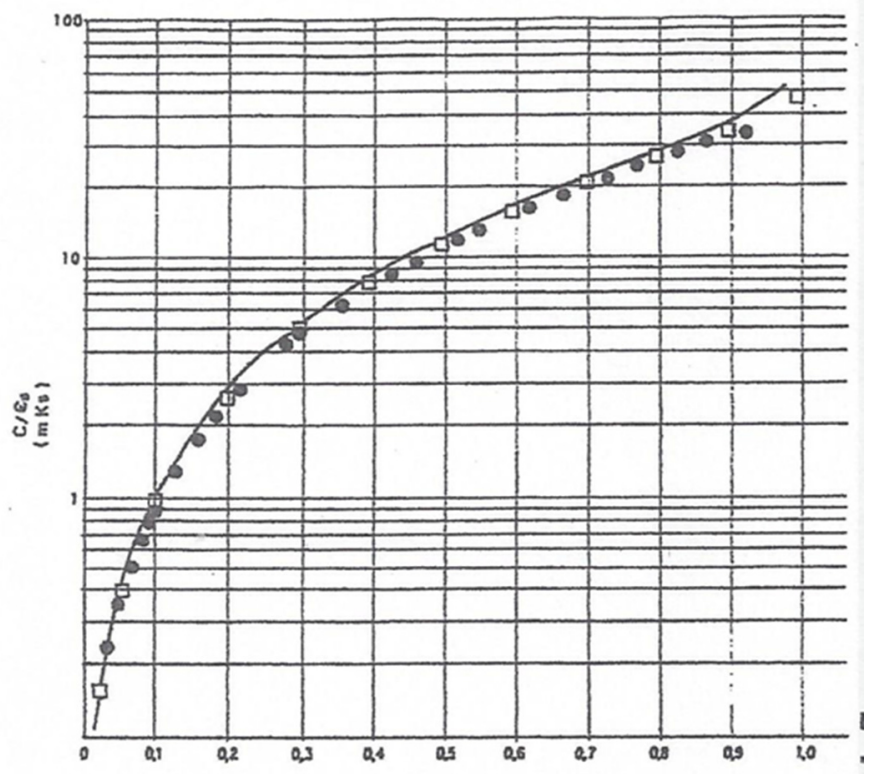

Figure 4: Capacitance vs. radius of the central electrode $(\delta=1$, $\left.\mathrm{x}_{0}=0.1\right)$. - Numerical solution $(29 \times 29$ nodes $)$. $\bullet$ Solution where the stored energy is minimized (5 constants). $\square$ Green function solution with uniform charge density at the central electrode.

\section{Conclusions}

From the derived theoretical results we proved how the liquid height in a tank can be determined without using a vertical electrode. For the case where we considered a constant surface charge the results derived were precise. Of course in a real measuring condition the effect of temperature variations and vibrations should be considered. 
The solution based on a Green function approach is easily changed so as to consider the case where we deal with a conductive liquid, just as the circuital model used in the numerical approach can be easily modified. In the case of the minimization of the stored energy, it is not clear if it can be extended to the case of a conductive liquid.

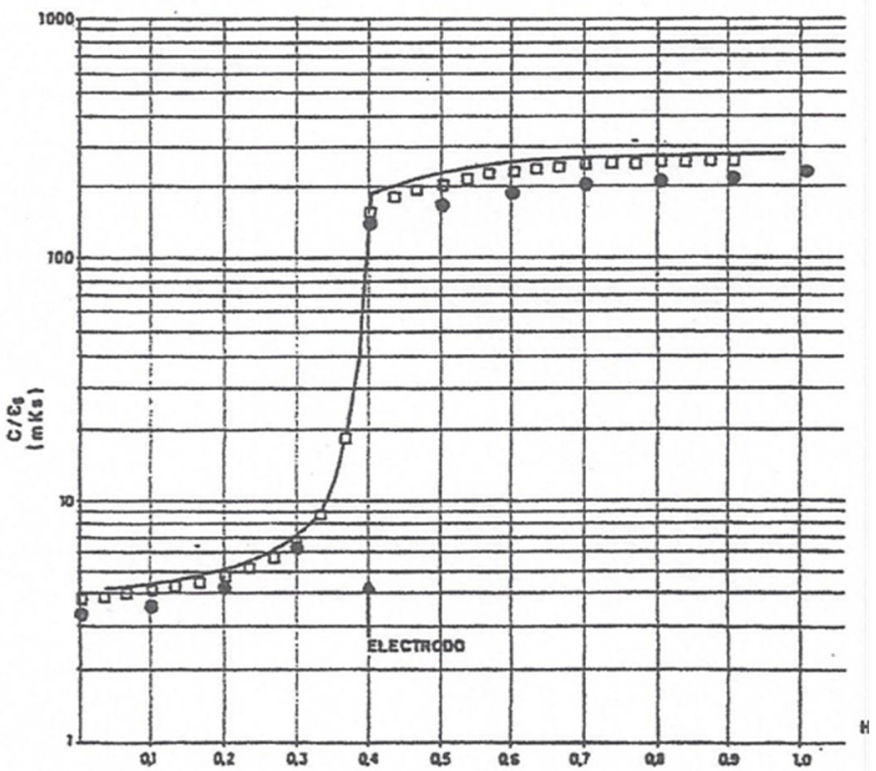

Figure 5: Capacitance vs. height of the liquid in the tank $\left(\delta=80, \mathrm{z}_{0}=0.6\right.$, $\mathrm{b}=0.362)$. — Numerical solution (29x29 nodes). • Solution where the stored energy is minimized (5 constants). $\square$ Green function solution with uniform charge density at the central electrode.

The details of the numerical solution are not included in the present paper. They are very similar to the discussion of the paper by Callarotti and Páez [8].

\section{References}

[1] Schuler E., "Practical Guide to $R F$ Level Control", Drexelbrook Engineering Company, Pennsylvania, 1981.

[2] Jackson J.D., “Classical Electrodynamics”, J. Wiley, New York, 1975.

[3] Abramowitz M. and Stegun I.A., "Handbook of mathematical functions", Dover, New York, 1968.

[4] Stratton J., "Electromagnetic theory", McGraw Hill, New York, 1941.

[5] Smythe W.R., "Static and Dynamic Electricity", McGraw Hill, New York, 1950

[6] Collin R.E., "Field theory of guided waves", McGraw Hill, New York, 1960. 
[7] Kron G., Equivalent circuit of the field equations of Maxwell, Proceedings of the IRE, 289-299, 1944.

[8] Callarotti R.C. and Páez E., "Efficient eigenvalue numerical solution for time dependent systems", Proceedings of the 16th International Conference on Computational Methods and Experimental Measurements, La Coruña (Spain), 1-13, 2013. 